\title{
Evaluasi Kesesuaian Lahan untuk Pengembangan Kopi Robusta (Coffea canephora) Menggunakan Sistem Informasi Geografis di Kecamatan Darul Hasanah Kabupaten Aceh Tenggara \\ (Evaluation of Land Suitability for Robusta Coffee (Coffea canephora) Development using Geographic Information System in Darul Hasanah Sub-District of Southeast Aceh Regency)
}

\author{
Ilham Raobi ${ }^{1}$, Yulia Dewi Fazlina ${ }^{1}$, Sugianto Sugianto ${ }^{1 *}$ \\ ${ }^{1}$ Program Studi Ilmu Tanah, Fakultas Pertanian, Universitas Syiah Kuala \\ *Corresponding author: sugianto@unsyiah.ac.id
}

\begin{abstract}
Abstrak. Kabupaten Aceh Tenggara ingin merencanakan kawasan pengembangan kopi robusta di Kecamatan Darul Hasanah yang banyak didominasi pada Kawasan Taman Nasional Gunung Leuser. Kawasan yang akan dijadikan pengembangan kopi robusta di Kecamatan Darul Hasanah telah menjadi kawasan kemitraan konservasi, untuk menjamin kelestarian lingkungan maka perlu dilakukan evaluasi kesesuaian lahan dengan menggunakan Sistem Informasi Geografis. Penelitian ini bertujuan untuk menentukan tingkat kesesuaian lahan kopi robusta dan mengetahui luas lahan yang berpotensi untuk pengembangan kopi robusta di Kecamatan Darul Hasanah Kabupaten Aceh Tenggara. Penelitian ini dilakukan dengan metode deksriptif dan survei yang selanjutnya dilakukan pencocokan (matching) kemudian data tersebut diolah dengan analisis spasial menggunakan Sistem Informasi Geografis (SIG) untuk pembuatan peta kesesuaian lahannya. Kesimpulan yang didapatkan pada penelitian ini yaitu, kesesuaian lahan pada kawasan yang akan dijadikan pengembangan kopi robusta di Kecamatan Darul Hasanah memiliki kesesuain lahan aktual cukup sesuai (S2) dan Sesuai Marginal (S3) dengan faktor pembatas curah hujan (wa) kemiringan lereng (eh), batuan di permukaan (lp) dan retensi hara (nr). Setelah dilakukkanya perbaikan dengan membuat terasering dan penambahan bahan organik, maka didapartkan kesesuaian lahan potensial cukup sesuai (S2) dengan faktor pembatas curah hujan (wa) dikarenakan curah hujan tidak dapat diperbaiki. Kawasan yang memilkii potensi untuk dijadikan kawasan pengembangan kopi robusta di kecamatan Darul Hasanah memiliki luas 353,76 hektar.
\end{abstract}

Kata kunci: Aceh Tenggara, Kopi Robusta, Kesesuain Lahan

\begin{abstract}
Southeast Aceh Regency wants to plan the development of robusta coffee in the Darul Hasanah subdistrict, which is dominated by the Gunung Leuser National Park area. The area that will be used as robusta coffee development in Darul Hasanah District has become a conservation partnership area, to ensure environmental sustainability it is necessary to evaluate the land using Geographic Information Systems. This study aims to determine the number of Robusta coffee fields and determine the potential land area for Robusta coffee development in Darul Hasanah District, Southeast Aceh Regency. This research was conducted using a descriptive and survey method which was then carried out (matching) and then the data was processed by spatial analysis using a Geographic Information System (GIS) for making land maps. The conclusion obtained in this study is that the land provision in the area that will be used as robusta coffee development in Darul Hasanah District has an actual land suitability that is quite suitable (S2) and Marginal Appropriate (S3) with the limiting factor of rainfall (wa), slope (eh), rock on the surface (lp) and nutrient retention (nr). After the repairs were made by making terracing and adding organic matter, a potential land allocation was obtained according to (S2) with the rainfall factor (wa) the rainfall could not be improved. The area that has the potential to be used as a robusta coffee development area in Darul Hasanah sub-district has an area of 353.76 hectares.
\end{abstract}

Keywords: Southeast Aceh, Robusta Coffee, Land Suitability

\section{PENDAHULUAN}

Provinsi Aceh merupakan salah satu penghasil kopi terbesar di Indonesia. Lingkungan alam yang ada di Provinsi Aceh memang sangat cocok dan sesuai untuk menghasilkan kopi dengan kualitas baik, sehingga produksi kopi di Provinsi Aceh yang mengalami peningkatan, salah satunya di Kabupaten Aceh Tenggara. Peningkatan produksi kopi di Kabupaten Aceh 
Tenggara pada tahun 2018, menghasilkan produksi kopi 60 ton dengan luas tanaman kopi 319 hektar, dan pada tahun 2019 meningkat menjadi 144 ton dengan luas tanaman kopi 378 hektar (Badan Pusat Statistik Provinsi Aceh, 2021). Kabupaten Aceh Tenggara ingin merencanakan pengembangan kopi robusta di Kecamatan Darul Hasanah. Hal ini dikarenakan Kecamatan Darul Hasanah pernah menjadi salah satu penghasil kopi robusta dan Kecamatan Darul Hasanah memiliki wilayah dengan ketinggian yang sesuai dengan tanaman kopi robusta.

Kawasan yang direncanakan untuk pengembangan kopi robusta di Kecamatan Darul Hasanah banyak di dominasi pada daerah kawasan lindung Taman Nasional Gunung Leuser (TNGL). Kawasan lindung dapat ditanami tanaman perkebunan berdasarkan kesepakatan dan kerjasama yang telah dilakukan oleh salah satu organisasi Persatuan Petani Kaki gunung Leuser (PPKGL) dengan beberapa pihak diantaranya, Kementrian Lingkungan Hidup dan Kehutanan, serta Balai Besar Taman Nasional Gunung Leuser menjadikan daerah tersebut menjadi kawasan kemiteraan konservasi, untuk menjaga kelestarian lingkungannya maka perlu dilakukan evaluasi kesesuaian lahan untuk mengetahui tentang hubungan antara kondisi lahan dengan syarat tumbuh tanaman kopi robusta serta memberikan perencanaan yang diharapkan nantinya kawasan pengembangan kopi robusta tersebut dapat berhasil sesuai dengan yang diharapkan.

Penentuan evaluasi kesesuaian lahan dapat dilakukan dengan memanfaatkan Sistem Informasi Geografis (SIG) yang nantinya akan menghasilkan output berupa gambaran atau peta kesesuaian lahan serta dapat mempersingkat waktu dalam menentukan kawasan yang sesuai dengan syarat pertumbuhan tanaman kopi robusta.

\section{METODE PENELITIAN}

Penelitian ini dilaksanakan di Kecamatan Darul Hasanah. Analisis data spasial dilakukan di Laboratorium Penginderaan Jauh dan Kartografi Fakultas Pertanian Universitas Syiah Kuala dan analisis tanah dilakukan di Laboratorium Penelitian Tanah dan Tanaman Universitas Syiah Kuala. Penelitian ini berlangsung dari bulan Februari sampai Mei 2021.

\section{MATERI DAN METODE}

\section{Alat dan Bahan}

Alat yang digunakan dalam penelitian ini ialah aplikasi ArcGis, Laptop, Kamera, Bor Tanah, pH Tancap, Altimeter, Clinometer, Salinity Meter, Plastik Sampel, dan Alat Tulis. Bahan yang digunakan dalam penelitian ini meliputi Peta Administrasi Kabupaten Aceh Tenggara, Peta Pola Ruang Kabupaten Aceh Tenggara, Peta Penggunaan Lahan Kabupaten Aceh Tenggara, Peta Kemiringan Lereng Kabupaten Aceh Tenggara, Peta Curah Hujan Kabupaten Aceh Tenggara dan Peta Jenis Tanah Kabupaten Aceh Tenggara serta Data Persyaratan Tumbuh Tanaman Kopi Robusta dan beberapa jenis larutan kimia untuk menganalisis contoh tanah di laboratorium seperti aquades, $\mathrm{K}_{2} \mathrm{Cr}_{2} \mathrm{O}_{7}, \mathrm{H}_{2} \mathrm{SO}_{4} 85 \%, \mathrm{H}_{2} \mathrm{O}_{2} 10 \%$ dan $30 \%, \mathrm{Na}_{4} \mathrm{P}_{2} \mathrm{O}_{7}, 10 \mathrm{H}_{2} \mathrm{O}, \mathrm{NaCl} 10 \%, \mathrm{NaOH} 30 \%, \mathrm{C}_{2} \mathrm{H}_{7} \mathrm{NO}_{2} \mathrm{pH}$ 7, etanol 80\%, asam nitrat $6 \mathrm{M}$, indikator definilamin $0,5 \%$, Indikator methyl red, larutan ferosulfat $1 \mathrm{M}$, larutan indikator asam boraks, larutan baku (Ca, Mg, K, Na) 1000 ppm, larutan lanthanum, dan larutan cesium.

\section{Metode Penelitian}

Penelitian ini menggunakan metode deskriptif dan survei yang kemudian dilanjutkan dengan metode pencocokan (matching) dengan syarat tumbuh tanaman kopi robusta. 


\section{Prosedur Penelitian}

Penelitian ini dilakukan dengan tiga tahap yaitu, tahap persiapan, tahap pra analisis dan tahap analisis data. Tahap persiapan yang dilakukan mencari data primer dan data sekunder, kemudian pada tahap pra analisis dimulai dengan pengolahan data dengan membuat peta satuan lahan dan survei lapangan untuk mengambil sampel tanah, pengambilan sampel tanah dilakukan secara acak. Kemudian selanjutnya tahap analisis data dengan menganalisis sampel tanah yang didapatkan dilapangan. Selanjutnya menganalisis data yang di dapatkan dari survei lapangan dengan data hasil laboratorium dan syarat pertumbuhan tanaman kopi robusta menggunakan Sistem Informasi Geografis untuk mendapatkan hasil berupa peta kesesuaian lahan untuk pengembangan kopi robusta di Kecamatan Darul Hasanah Kabupaten Aceh Tenggara.

\section{HASIL DAN PEMBAHASAN}

\section{Pola Ruang}

Berdasarkan pola ruang Kabupaten Aceh Tenggara, kawasan yang akan dijadikan pengembangan kopi robusta masuk kedalam kawasan lindung yang memiliki luas 400,11 hektar dan hanya sedikit terdapat di kawasan budidaya yaitu 1,94 hektar. Sebahagian besar kawasan lindung pada lokasi penelitian di Kecamatan Darul Hasanah masuk kedalam Kawasan Taman Nasional Gunung Leuser. Organisasi Persatuan Petani Kaki Gunung Leuser (PPKGL) telah bekerja sama dengan dengan Kementerian Lingkungan Hidup dan Kehutanan serta Balai Besar Taman Nasional Gunung Leuser bahwasanya lahan yang sudah terlanjur dipakai oleh masyarakat, dapat dimanfaatkan untuk tanaman perkebunan karena sudah beralih fungsi menjadi kawasan kemitraan konservasi, namun tetap menjaga kelestarian lingkungan.

\section{Kemiringan Lereng}

Kemiringan lereng di lokasi penelitian terbagi menjadi lima kategori kemiringan lereng dapat dilihat pada Tabel 1 .

Tabel 1. Kemiringan Lereng

\begin{tabular}{cccc}
\hline Kemiringan Lereng & Keterangan & Luas (ha) & Persentase (\%) \\
\hline $0-8 \%$ & Datar & 5,55 & 1,38 \\
$8-15 \%$ & Landai & 47,20 & 11,74 \\
$15-25 \%$ & Agak Curam & 121,99 & 30,34 \\
$25-45 \%$ & Curam & 179,02 & 44,53 \\
$>45 \%$ & Sangat Curam & 48,29 & 12,01 \\
\hline Total & & 402,05 & 100
\end{tabular}

Sumber: Bappeda Aceh Tenggara, 2012

\section{Satuan Peta Lahan}

Satuan Peta Lahan adalah satuan lahan yang memiliki kesamaan dari parameter satuan lahan yang digunakan. Satuan Peta lahan ini didapatkan berdasarkan hasil overlay data kemiringan lereng dan tutupan lahan serta penambahan jenis tanah. Satuan peta lahan pada lokasi penelitian dapat dilihat pada Tabel 2. 
Tabel 2. Satuan Peta Lahan

\begin{tabular}{|c|c|c|c|}
\hline No. SPL & $\begin{array}{l}\text { Kemiringan } \\
\text { Lereng }\end{array}$ & Tutupan Lahan & Jenis Tanah \\
\hline SPL1 & $0-8 \%$ & Pertanian Lahan Kering & $\begin{array}{l}\text { Podsolik Merah Kuning, } \\
\text { Latosol, Litosol dan } \\
\text { Alluvial }\end{array}$ \\
\hline SPL2 & $8-15 \%$ & Pertanian Lahan Kering & $\begin{array}{l}\text { Podsolik Merah Kuning, } \\
\text { Latosol, Litosol dan } \\
\text { Alluvial }\end{array}$ \\
\hline SPL3 & $15-25 \%$ & Pertanian Lahan Kering dan Belukar & $\begin{array}{l}\text { Podsolik Merah Kuning, } \\
\text { Latosol, Litosol dan } \\
\text { Alluvial }\end{array}$ \\
\hline SPL4 & $25-45 \%$ & Pertanian Lahan Kering dan Belukar & $\begin{array}{l}\text { Podsolik Merah Kuning, } \\
\text { Latosol, Litosol dan } \\
\text { Alluvial }\end{array}$ \\
\hline SPL5 & $45 \%$ & Pertanian Lahan Kering dan Belukar & $\begin{array}{l}\text { Podsolik Merah Kuning, } \\
\text { Latosol, Litosol dan } \\
\text { Alluvial }\end{array}$ \\
\hline SPL6 & $0-8 \%$ & $\begin{array}{l}\text { Hutan Lahan Kering Sekunder, } \\
\text { Pertanian Lahan Kering dan Belukar }\end{array}$ & $\begin{array}{l}\text { Podsolik Merah Kuning, } \\
\text { Latosol dan Litosol }\end{array}$ \\
\hline SPL7 & $8-15 \%$ & $\begin{array}{l}\text { Hutan Lahan Kering Sekunder, } \\
\text { Pertanian Lahan Kering dan Belukar }\end{array}$ & $\begin{array}{l}\text { Podsolik Merah Kuning, } \\
\text { Latosol dan Litosol }\end{array}$ \\
\hline SPL8 & $15-25 \%$ & $\begin{array}{l}\text { Hutan Lahan Kering Sekunder, } \\
\text { Pertanian Lahan Kering dan Belukar }\end{array}$ & $\begin{array}{l}\text { Podsolik Merah Kuning, } \\
\text { Latosol, Litosol dan } \\
\text { Alluvial }\end{array}$ \\
\hline SPL9 & $25-45 \%$ & $\begin{array}{l}\text { Hutan Lahan Kering Sekunder, } \\
\text { Pertanian Lahan Kering dan Belukar }\end{array}$ & $\begin{array}{l}\text { Podsolik Merah Kuning, } \\
\text { Latosol, Litosol dan } \\
\text { Alluvial }\end{array}$ \\
\hline SPL10 & $>45 \%$ & $\begin{array}{l}\text { Hutan Lahan Kering Sekunder, } \\
\text { Pertanian Lahan Kering dan Belukar }\end{array}$ & $\begin{array}{l}\text { Podsolik Merah Kuning, } \\
\text { Latosol dan Litosol }\end{array}$ \\
\hline
\end{tabular}

Berdasarkan Tabel 2, satuan peta lahan dibedakan menjadi 10, yang dibedakan berdasarkan kelas lereng, penggunaan lahan dan jenis tanah. Kelas kemirngan lereng sangat berpengaruh terhadap penentuan kesesuaian lahan. Kemudian tutupan lahan yang terdapat pada satuan peta lahan dibagi menjadi 3 yaitu: hutan lahan kering sekunder, pertanian lahan kering dan belukar. Jenis tanah terbagi menjadi 4 yaitu Podsolik Merah Kuning, Latosol, Litosol dan Alluvial.

\section{Kesesuaian Lahan Aktual}

Kesesuaian lahan Aktual merupakan kesesuaian lahan berdasarkan sifat biofisik tanah atau sumberdaya lahan sebelum dilakukan upaya perbaikan yang diperlukan untuk mengatasi kendala yang terjadi pada suatu lahan. Kesesuaian lahan aktual pada lokasi penelitian dapat dilihat pada Tabel 3 .

Berdasarkan Tabel 3, menunjukkan bahwasanya kelas kesesuaian lahan aktual pada lokasi penelitian yaitu cukup sesuai (S2) dan sesuai marginal (S3) dengan faktor pembatas curah Hujan (wa), kemiringan lereng (eh), batuan dipermukaan (lp) dan retensi hara (nr). Kawasan yang dapat dimanfaatkan menjadi kawasan pengembangan kopi robusta di Kecamatan Darul Hasanah memiliki luas 353,76 hektar. Kesesuaian lahan yang memiliki kelas kesesuaian lahan tidak sesuai (N) memiliki luas 48,29 hektar. Hal ini disebabkan karena bahaya erosi karena kemiringan lerengnya lebih dari $>45 \%$. Kesesuaian Lahan Potensial dapat dilihat pada Gambar 1. 
Tabel 3. Penilaian Kesesuaian Lahan Aktual

\begin{tabular}{|c|c|c|c|c|}
\hline \multirow{2}{*}{ No SPL } & \multirow{2}{*}{$\begin{array}{c}\text { Kelas Kesesuaian } \\
\text { LahanAktual }\end{array}$} & \multirow{2}{*}{ Faktor Pembatas } & \multicolumn{2}{|l|}{ Luas } \\
\hline & & & ha & $\%$ \\
\hline 1 & S2wa, nr,eh & $\begin{array}{l}\text { Ketersediaan Air (curah hujan), Retensi } \\
\text { Hara (KTK dan C-Organik) }\end{array}$ & 2,61 & 0,65 \\
\hline 2 & S2wa,nr,eh & $\begin{array}{l}\text { Ketersediaan Air (curah hujan), Retensi } \\
\text { Hara (KTK dan C-Organik), Bahaya Erosi } \\
\text { (lereng) }\end{array}$ & 34,33 & 8,54 \\
\hline 3 & S3wa,nr,eh & $\begin{array}{l}\text { Ketersediaan air (curah hujan), Retensi } \\
\text { Hara (KTK dan C-Organik),Bahaya } \\
\text { Erosi (lereng) }\end{array}$ & 75,44 & 18,76 \\
\hline 4 & S3wa,nr,eh & $\begin{array}{l}\text { Ketersediaan Air (curah hujan), Retensi } \\
\text { Hara (KTK dan C-Organik),Bahaya Erosi } \\
\text { (lereng) }\end{array}$ & 44,55 & 11,08 \\
\hline 5 & $\mathrm{~N}$ & - & 8,84 & 2,20 \\
\hline 6 & S2wa,lp,nr & $\begin{array}{l}\text { Ketersediaan Air (curah hujan), Penyiapan } \\
\text { Lahan (batuan permukaan), Retensi Hara } \\
\text { (KTK dan C-Organik) }\end{array}$ & 2,94 & 0,73 \\
\hline 7 & S2wa,lp,nr,eh & $\begin{array}{l}\text { Ketersediaan Air (curah hujan), } \\
\text { Penyiapan Lahan (batuan permukaan), } \\
\text { Retensi Hara (KTK dan C-Organik), } \\
\text { Bahaya Erosi (Lereng) }\end{array}$ & 12,87 & 3,20 \\
\hline 8 & S3wa,lp,nr,eh & $\begin{array}{l}\text { Ketersediaan Air (curah hujan), } \\
\text { Penyiapan Lahan (batuan permukaan), } \\
\text { Retensi Hara (KTK), Bahaya Erosi } \\
\text { (Lereng) }\end{array}$ & 46,54 & 11,58 \\
\hline 9 & S3wa,lp,nr,eh & $\begin{array}{l}\text { Ketersediaan Air (curah hujan), Penyiapan } \\
\text { Lahan (batuan permukaan), Retensi Hara } \\
\text { (KTK), Bahaya Erosi (Lereng) }\end{array}$ & 134,47 & 33,45 \\
\hline 10 & $\mathrm{~N}$ & - & 39,45 & 9,81 \\
\hline Jumlah & & & 402,05 & 100,00 \\
\hline
\end{tabular}

\section{Kesesuaian Lahan Potensial}

Kesesuaian lahan potensial merupakan kesesuain lahan yang telah di capai setelah dilakukannya perbaikan lahan, hasil yang didapatkan dari 10 Satuan Peta Lahan (SPL) kesesuaian lahan cukup sesuai (S2) dan sesuai marginal (S3) dengan faktor pembatas curah hujan (wa), kemiringan lereng (eh), retensi hara (nr), batuan dipermukaan (lp). Kesesuaian Lahan Potensial yang bisa dicapai pada lokasi penelitian ini dengan faktor pembatas kemiringan lereng (eh) dapat dilakukan upaya perbaikan dengan pembuatan terasering. Faktor pembatas kurangnya retensi hara (nr) dapat dilakukan upaya perbaikan dengan menambahkan bahan organik dan pengapuran, kemudian faktor pembatas batuan dipermukaan (lp) dapat dilakukan upaya perbaikan dengan pembersihan lahan. Hasil kesesuaian lahan potensial yang didapatkan cukup sesuai (S2) dengan faktor pembatas curah hujan (wa) dikarenakan curah hujan tidak dapat dilakukan upaya perbaikan. Kesesuaian lahan potensial dapat dilihat pada Tabel 4 dan Gambar 2. 


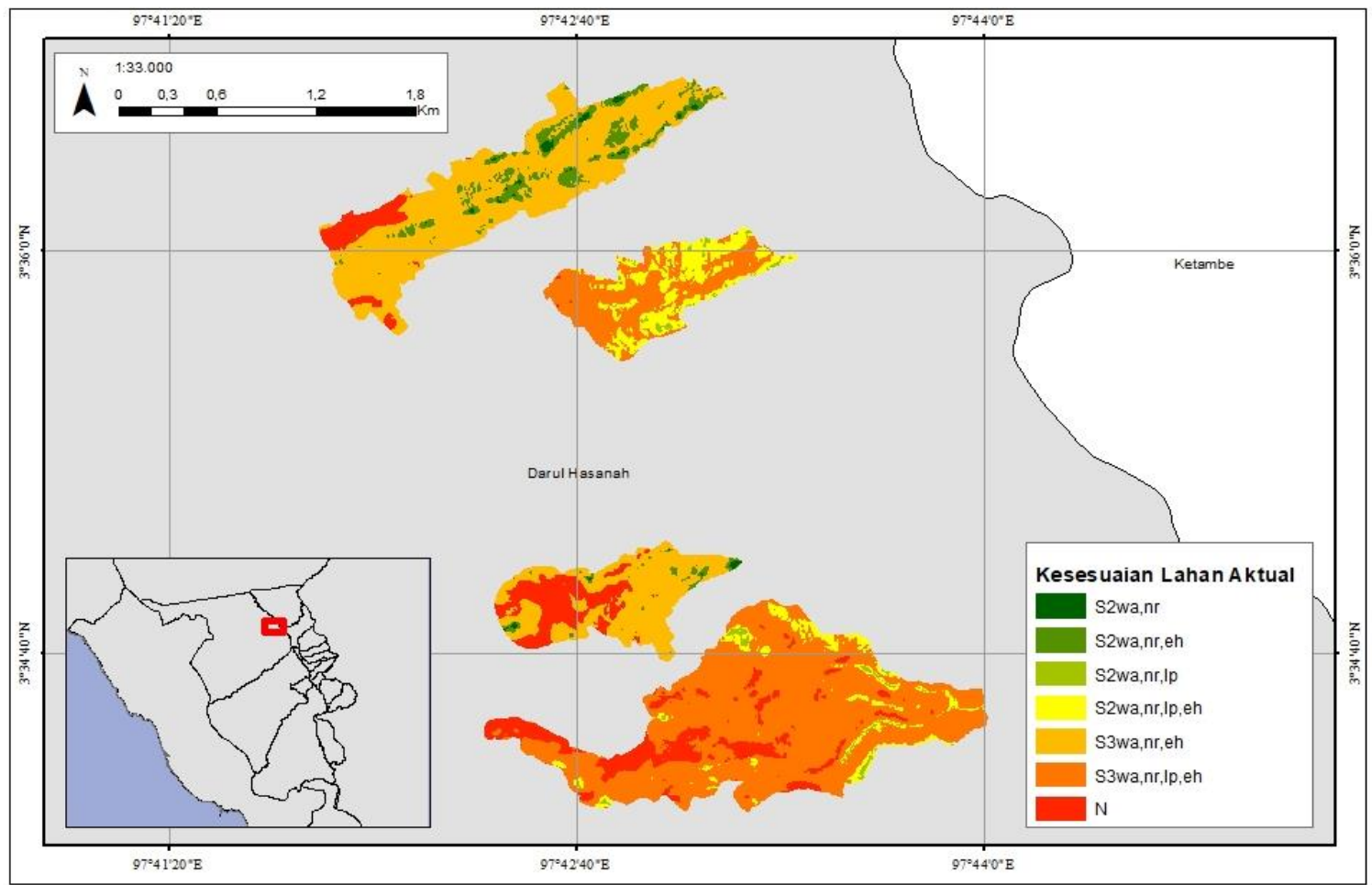

Gambar 1. Peta Kesesesuaian Lahan Aktual

Tabel 4. Penilaian Kesesuaian Lahan Potensial

\begin{tabular}{|c|c|c|c|c|c|c|}
\hline \multirow{2}{*}{$\begin{array}{l}\text { No } \\
\text { SPL }\end{array}$} & \multirow{2}{*}{$\begin{array}{c}\text { Kelas } \\
\text { Kesesuaian } \\
\text { Aktual }\end{array}$} & \multirow{2}{*}{ Faktor Pembatas } & \multirow{2}{*}{ Upaya Perbaikan } & \multirow{2}{*}{$\begin{array}{c}\text { Kelas } \\
\text { Kesesuaian } \\
\text { Potensial }\end{array}$} & \multicolumn{2}{|c|}{ Luas } \\
\hline & & & & & $\mathrm{Ha}$ & $\%$ \\
\hline \multirow[t]{3}{*}{1} & S2wa,nr & Curah Hujan & - & S2wa & 2,61 & 0,65 \\
\hline & & C-Organik & Penambahan Bahan Organik & & & \\
\hline & & $\overline{\text { KTK }}$ & Pengapuran & & & \\
\hline \multirow[t]{4}{*}{2} & S2wa,nr,eh & Curah Hujan & - & S2wa & 34,33 & 8,54 \\
\hline & & C-Organik & Penambahan Bahan Organik & & & \\
\hline & & $\overline{\text { KTK }}$ & Pengapuran & & & \\
\hline & & Lereng & Pembuatan Terasering & & & \\
\hline \multirow[t]{4}{*}{3} & S3wa,nr,eh & Curah Hujan & - & S2wa & 75,44 & 18,76 \\
\hline & & C-Organik & Penambahan Bahan Organik & & & \\
\hline & & KTK & Pengapuran & & & \\
\hline & & Lereng & Pembuatan Terasering & & & \\
\hline \multirow[t]{4}{*}{4} & S3wa,nr,eh & Curah Hujan & - & S2wa & 44,55 & 11,08 \\
\hline & & C-Organik & Penambahan Bahan Organik & & & \\
\hline & & KTK & Pengapuran & & & \\
\hline & & Lereng & Pembuatan Terasering & & & \\
\hline 5 & $\mathrm{~N}$ & - & - & & 8,84 & 2,20 \\
\hline \multirow[t]{2}{*}{6} & S2wa,lp,nr & Curah Hujan & - & S2wa & 2,94 & 0,73 \\
\hline & & Batuan di Permukaan & PembersihanLahan & & & \\
\hline
\end{tabular}




\begin{tabular}{|c|c|c|c|c|c|c|}
\hline \multirow{3}{*}{$\begin{array}{l}\text { No } \\
\text { SPL }\end{array}$} & \multirow{3}{*}{$\begin{array}{c}\text { Kelas } \\
\text { Kesesuaian } \\
\text { Aktual }\end{array}$} & \multirow{3}{*}{ Faktor Pembatas } & \multirow{3}{*}{ Upaya Perbaikan } & \multirow{5}{*}{$\begin{array}{c}\text { Kelas } \\
\text { Kesesuaian } \\
\text { Potensial }\end{array}$} & \multicolumn{2}{|c|}{ Luas } \\
\hline & & & & & & \\
\hline & & & & & $\mathrm{Ha}$ & $\%$ \\
\hline & & C-Organik & Penambahan Bahan Organik & & & \\
\hline & & KTK & Pengapuran & & & \\
\hline \multirow[t]{5}{*}{7} & S2wa,lp,nr,eh & Curah Hujan & - & S2wa & 12,87 & 3,20 \\
\hline & & Batuan di Permukaan & PembersihanLahan & & & \\
\hline & & C-Organik & Penambahan Bahan Organik & & & \\
\hline & & KTK & Pengapuran & & & \\
\hline & & Lereng & Pembuatan Terasering & & & \\
\hline \multirow[t]{5}{*}{8} & S3wa,lp,nr,eh & Curah Hujan & - & S2wa & 46,54 & 11,58 \\
\hline & & Batuan di Permukaan & PembersihanLahan & & & \\
\hline & & C-Organik & Penambahan Bahan Organik & & & \\
\hline & & KTK & Pengapuran & & & \\
\hline & & Lereng & Pembuatan Terasering & & & \\
\hline \multirow[t]{5}{*}{9} & S3wa,lp,nr,eh & Curah Hujan & - & S2wa & 134,47 & 33,45 \\
\hline & & Batuan di Permukaan & PembersihanLahan & & & \\
\hline & & C-Organik & Penambahan Bahan Organik & & & \\
\hline & & $\overline{\mathrm{KTK}}$ & Pengapuran & & & \\
\hline & & Lereng & Pembuatan Terasering & & & \\
\hline 10 & $\mathrm{~N}$ & - & - & & 39,45 & 9,81 \\
\hline Jumlah & & & & & 402,05 & 100,00 \\
\hline
\end{tabular}

\section{KESIMPULAN DAN SARAN}

Tingkat kesesuaian lahan tanaman kopi robusta di Kecamatan Darul Hasanah Kabupaten Aceh Tenggara memiliki kesesuaian lahan aktual tergolong cukup sesuai (S2) dan sesuai marginal (S3) dengan faktor pembatas curah hujan (wa), kemiringan lereng (eh), batuan di permukaan (lp) dan retensi hara (nr). Tingkat kesesuaian lahan potensial tergolong cukup sesuai (S2) dengan faktor pembatas curah hujan (wa). Kawasan yang berpotensi untuk pengembangan kopi robusta di kecamatan Darul Hasanah Kabupaten Aceh Tenggara memiliki luas 353,76 hektar. Saran untuk penlitian ini ialah upaya untuk meningkatkan kesesuaian lahan di kawasan pengembangan kopi robusta pada Kecamatan Darul Hasanah Kabupaten Aceh Tenggara perlu penambahan bahan organik dan pembuatan terasering yang kemungkinan memerlukan biaya yang sedikit besar dan tentunya memerlukan bantuan dari pemerintah untuk terwujudnya kawasan yang akan dijadikan sebagai kawasan pengembangan kopi robusta di Kecamatan Darul Hasanah Kabupaten Aceh Tenggara 


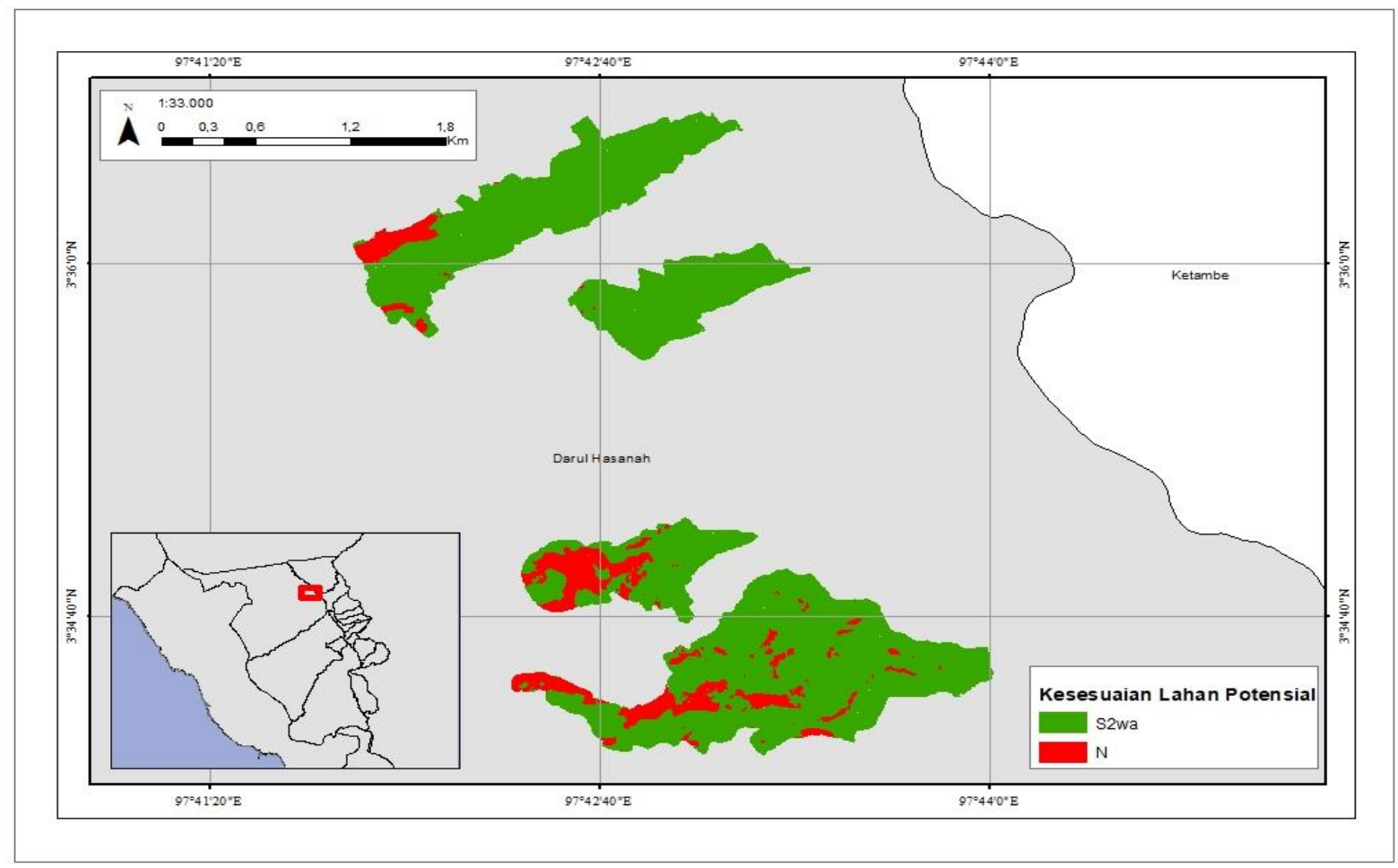

Gambar 2. Peta Kelas Kesesuaian Lahan Potensial

\section{DAFTAR PUSTAKA}

Badan Pusat Statistik Indonesia. 2017. Statistik Indonesia 2017. Jakarta.

Badan Pusat Statistik Provinsi Aceh. 2020. Provinsi Aceh dalam Angka 2021. Banda Aceh.

Balai Besar Litbang Sumberdaya Lahan Pertanian. 2011. Petunjuk Teknis Evaluasi Lahan untuk Komoditas Pertanian Edisi Revisi 2011. Badan Besar Penelitian dan Pengembangan Sumberdaya Lahan Pertanian. Bogor.

Bappeda Kabupaten Aceh Tenggara. 2012. Peta Kemiringan Lereng Kabupaten Aceh Tenggara. Pemerintah Kabupaten Aceh Tenggara. Aceh Tenggara.

Djaenudin, D., Marwan, H., Subagjo, H., dan A. Hidayat. 2011. Petunjuk Teknis Evaluasi Lahan untuk Komoditas Pertanian. Balai Besar Litbang Sumberdaya Lahan Pertanian, Badan Litbang Pertanian. Bogor.

Handayani, D. 2005. Pemanfaatan Analisis Spasial Untuk Pengolahan Data Spasial Sistem Informasi Geografi. Jurnal Teknologi Informasi DINAMIK. 10(2), pp. 108-116.

Harjowigeno, S. dan Widiatmaka. 2007. Kesesuaian Lahan dan Perencanaan Tata Guna Lahan. Gadjah Mada University Press. Yogyakarta.

Tjokrokusumo, S.W. 2002. Kelas Kesesuaian Lahan Sebagai Dasar Pengembangan Pertanian Ramah Lingkungan di Daerah Aliran Sungai. Jurnal Teknologi Lingkungan. 3(2), pp.36-143.

Pinatih, I. D. A. S. P., T. B. Kusmiyarti, dan K. D. Susila. 2015. Evaluasi Kesuburan Tanah Pada Lahan Pertanian di Kecamatan Denpasar Selatan. Jurnal Agroekoteknologi Tropika. 4(4), pp.283-292.

Ritung, S., Wahyunti, F. Agus, dan H. Hidayat. 2007. Panduan Evaluasi Kesesuaian Lahan dengan Contoh Peta Arahan Penggunaan Universitas Sumatera Utara Lahan Kabupaten Aceh Barat. Balai Penelitian Tanah dan World Agroforestry (ICRAF). Bogor. 